\title{
Internacionalização de terras no Brasil: perspectivas para o setor de plantações de madeira
}

\section{Internacionalização de terras no Brasil: perspectivas para o setor de plantações de madeira}

\section{D0I: 10.5752/P.2317-773X.2017v5.n2.p132}

1. Olympio Barbanti Jr. é professor-adjunto do curso de Relações Internacionais da Universidade Federal do ABC (UFABC) e coordenador do Núcleo de Estudos Estratégicos sobre Democracia, Desenvolvimento e Sustentabilidade (NEEDDS/UFABC). Contato: olympio. barbanti@ufabc.edu.br. ORCID: orcid. org/0000-0003-2888-6811
Olympio Barbanti Jr. ${ }^{1}$

Recebido em: 15 de Agosto de 2017

Aceito em: 16 de outubro de 2017

\section{RESUMO}

Análises sobre internacionalização de terras têm partido de duas premissas: a de que a corrida por terras tem a função principal de promover a produção de alimentos, e a de que a falta de informações sobre transações é derivada do fato deg o cadastro mantido pelo governo ser de preenchimento voluntário. Esse trabalho argumenta que não ocorre falta de informações, mas sim um controle de informações que, por lei, devem existir. O texto também questiona se a agropecuária deverá ser a principal finalidade dos investimentos. Para isso, analisa o preço da terra no Brasil, e as condições de acesso e produtividade à luz dos debates sobre land grabbing, e argumenta que as dimensões de usos múltiplos e flexíveis pautam os investimentos por possibilitar maior retorno sobre o capital com menores riscos, o que ocorre no setor de madeira. O Brasil possui a maior produtividade mundial em florestas plantadas, as quais têm observado grande crescimento em todo o mundo. Por terem usos múltiplos e flexíveis, as florestas plantadas devem atrair land grabbing ligado a atuais processos produtivos industriais, e também à nova bioeconomia. Resta saber como o país irá se inserir nessa nova especialização produtiva

Palavras-chave: Internacionalização de terras. Plantações florestais. Economia política agrária.

\footnotetext{
ABSTRACT

Analyzes of land grabbing have come from two assumptions: that the run for land acquisition has the main function of promoting food production, and that the lack of official information about purchases from foreigners is due to the voluntary character of the registry maintained by the government. This work argues that there is no lack of information, but rather a control of information that, by law, must exist. The text also questions whether agriculture and cattle-ranching should be the main purpose of investments. In order to do so, it analyzes the price of land in Brazil, and the conditions of access and productivity in the light of the debates about land grabbing, and argues that the possibilities of multiple and flexible uses guide investments by allowing greater
} 
return on capital with lower risks. Brazil has a privileged position in forest plantations, a sector which has observed great growth throughout the world. Planted forests should attract large-scale land transactions and be the resource input to existing industrial processes, as well as for the new bioeconomy. It remains to be seen how the country will insert itself in this new specialization of production.

Key words: Land-grabbing. Forest plantations. Agrarian political economy.

Introdução

O processo de internacionalização de terras, corrida por terras, ou land grabbing, tem sido analisado a partir de um foco principal na incorporação de áreas rurais pela agricultura capitalista com o objetivo primordial de produção de alimentos e de controle de recursos naturais, como água e biodiversidade. A literatura internacional e nacional que versa sobre o tema reconhece, no entanto, que faltam estudos a respeito de investimentos internacionais em terras com outros objetivos que não sejam a produção de alimentos (EDELMAN, 2016). Este artigo busca contribuir para esse conhecimento a partir de um debate sobre as condições empíricas relativas à internacionalização de terras no Brasil, as condições de acesso e os possíveis usos da terra. O Brasil já é o segundo produtor mundial de alimentos, e deverá se tornar o primeiro na próxima década. Nesse contexto, a incorporação de terras brasileiras para produção agropecuária deverá crescer, quer sob o controle do capital nacional ou internacional. No entanto, outros usos devem ser considerados. A fertilidade do solo, a disponibilidade de água e a insolação tornam as terras brasileiras atrativas para diversos usos, dentre os quais desponta um aumento da demanda nacional e internacional por madeira. É particularmente relevante o fato de que as florestas plantadas no Brasil possuem a maior produtividade do mundo (NALI; RIBEIRO; HORA, 2015; INDÚSTRIA BRASILEIRA DE ÁRVORES, 2016), que ocorre um aumento da produção madeireira associada à agropecuária, e que tecnologias em início de implantação propiciam que a madeira venha a ser em breve o principal ativo da nova bioeconomia.

Para analisar esse quadro, esse trabalho se organiza em quatro seções, além dessa introdução. A primeira examina informações oficiais sobre a propriedade por estrangeiros da terra no Brasil, mostrando a falta de informações do governo sobre estabelecimentos rurais pertencentes a pessoas físicas e jurídicas estrangeiras. No entanto, nas regiões nas quais as informações são mais confiáveis aparece com destaque o reflorestamento. A segunda seção trata do mercado de terras, analisando preços e o significado de uma iniciativa do Legislativo e do Executivo brasileiros que facilita a venda de terras para estrangeiros. Essa proposta é analisada à luz de suas consequências para o mercado de terras no Brasil, e à luz da evolução dos preços praticados. A terceira parte aprofunda a análise da demanda por terra no Brasil em relação aos principais produtos alimentares, e à madeira. Argumenta-se que a produção rural - alimentar ou não - que possua mais possibilidades de usos múltiplos e flexíveis deve ter a preferência de investidores, pelas possibilidades de retorno. Entre 
elas destaca-se a madeira. $\mathrm{O}$ trabalho pondera sobre as características das plantações para diferentes usos, e os possíveis impactos da ampliação da produção madeireira. Na quarta seção, o artigo apresenta considerações finais que amarram a discussão e conclui com um resumo do argumento que se desenvolveu ao longo do texto.

\section{A situação da propriedade de terras no brasil}

e a proposta de venda a estrangeiros

Provavelmente a afirmação mais correta que se possa fazer sobre a quantidade e localização das terras brasileiras pertencentes a estrangeiros é a de que não existem dados corretos, divulgados. A fragilidade dos cadastros nacionais sobre propriedade de terras persiste ao longo dos anos. Uma leitura crítica dessas falhas leva a crer que não são incapacidades, mas sim o reflexo de um direcionamento político que beneficia os proprietários de terra, em especial os grandes proprietários. Para compreender esse contexto, cabe analisar primeiramente a concentração fundiária no Brasil.

A concentração fundiária no Brasil foi estimada pela última vez no censo realizado pelo Instituto Brasileiro de Geografia e Estatística (IBGE) em 2006. A Tabela I, a seguir, apresenta os dados.

Tabela I. Número e área dos estabelecimentos por grupos de área total - Brasil - 2006.

\begin{tabular}{c|c|c|c|c}
\hline Grupos de área total & $\begin{array}{c}\text { Número de } \\
\text { estabelecimentos } \\
\text { (unidades) }\end{array}$ & $\%$ & $\begin{array}{c}\text { Área dos } \\
\text { estabelecimentos } \\
\text { (hectares) }\end{array}$ & $\%$ \\
\hline Menos de 10 ha & 2.477 .071 & 47,86 & 7.798 .607 & 2,36 \\
\hline 10 a menos de 100 ha & 1.971 .577 & 38,09 & 62.893 .091 & 19,06 \\
\hline $\begin{array}{c}100 \text { a menos de } 1.000 \\
\text { ha }\end{array}$ & 424.906 & 8,21 & 112.696 .478 & 34,16 \\
\hline 1.000 ha e mais & 46.911 & 0,91 & 146.553 .218 & 44,42 \\
\hline Total & 5.175 .489 & 100,00 & 329.941 .393 & 100,00 \\
\hline
\end{tabular}

Fonte: INSTITUTO BRASILEIRO DE GEOGRAFIA E ESTATÍSTICA, 2009, p. 107)

Os dados mostram que os estabelecimentos rurais com menos de 10 hectares (ha) somavam 2.477 .071 unidades e representavam $47,86 \%$ do total de estabelecimentos em 2006. Essas pequenas propriedades representavam, juntas, apenas $2,36 \%$ do total de áreas dos estabelecimentos rurais particulares cadastrados. Por sua vez, os estabelecimentos de grande porte, com 1000 ha ou mais, somavam 46.911 unidades, apenas $0,91 \%$ do total, mas possuíam pouco mais de 146 milhões de hectares, representando $44,42 \%$ do total das terras rurais em estabelecimentos.

Esses dados, referentes ao último censo agropecuário realizado, ilustram a desigualdade na propriedade da terra no Brasil. Desigualdade que deve ter aumentado em grandes proporções na década. Essa alteração pode ser analisada por meio do Sistema Nacional de Cadastro Rural (SNCR), do Instituto Nacional de Colonização e Reforma Agrária (Incra). Em 2016 os dados consolidados do SNCR indicavam haver 5.766.542 unidades rurais no Brasil, ou seja, 591.053 unidades a mais (11,4\%) do que os 
5.175.489 hectares existentes 10 anos atrás (INSTITUTO NACIONAL DE COLONIZAÇÃO E REFORMA AGRÁRIA, 2016). No entanto, a área total cadastrada no SNCR era de 521.837.119 hectares, o que representa um incremento de 191.895.726 hectares, ou seja, um aumento de 58,16\% na área total de terras registradas pelo órgão agrário do país, o que indica ter ocorrido um aumento na área das propriedades rurais - que pode refletir um aumento real do número de propriedades existentes, ou um aumento no número de propriedades registradas. Como na última década houve continuidade do êxodo rural, e aumento dos investimentos capitalistas em terra, é de se esperar que a propriedade dessas terras tenha se concentrado em proporções ainda mais elevadas, o que deve ser verificado no censo agropecuário de 2017, cujos resultados devem ser divulgados no início de 2018.

Os dados do SNCR (2016) também indicam que existem 9.322 imóveis rurais de titularidade pública, com 160.062.972 hectares. Somados àqueles de titularidade privada, tem-se um total de 681.900 .091 hectares. Como o território brasileiro possui 851.576 .700 hectares, faltam 169.676.609 hectares no cadastro federal. São praticamente 170 milhões de hectares, ou cerca de $20 \%$ de terras brasileiras cuja titularidade é desconhecida, ou são terras devolutas.

Por meio da Lei de Acesso à Informação foram solicitados ao Incra dados da quantidade, área, tipo de propriedade (pessoa física e jurídica) e localização de terras pertencentes a estrangeiros no Brasil. Dados sobre propriedades rurais no Brasil, de brasileiros e estrangeiros, são recebidos e organizados pelas 30 superintendências regionais do Incra a partir de informação dos cartórios existentes nos municípios, e repassados à sede do Instituto, em Brasília. As informações solicitadas foram disponibilizadas em outubro de 2016 a esse autor e, ao mesmo tempo, a um jornalista que também fizera o pedido. Pela primeira vez o Incra apresentou os dados organizados por pessoa física e pessoa jurídica, agrupados por município e estado da federação. Os dados incluem nome do município, nome da pessoa ou jurídica proprietária, CPF ou CNPJ, código do imóvel rural, denominação do imóvel, data da atualização, área informada, área registrada, destinação (tipo da principal atividade produtiva), país de origem do estrangeiro, entre outros dados.

No entanto, as primeiras tabelas enviadas pelo Incra somavam cerca de 3,4 milhões de hectares pertencentes a estrangeiros, um número que chamou a atenção pelo fato de que o mesmo órgão fornecera a Sauer e Leite em 2012 dados que indicavam haver 4.349.074 hectares em imóveis rurais sob a propriedade de estrangeiros, um seja, praticamente um milhão de hectares a menos do que seis anos atrás. Em relação a pessoas físicas (PF), foram apresentados os registros de 29.892 imóveis rurais cujo principal proprietário (com mais de $50 \%$ do valor do imóvel em escritura) é estrangeiro PF. Isso representa apenas $0,5 \%$ do total de 5.766 .542 imóveis no SNCR. Infelizmente, os dados sobre área não são confiáveis: há vários dados faltando, em especial para o estado do Paraná, e há diversos números repetidos e com valores inteiros, o que sugere que foram "arredondados".

No cadastro de pessoas jurídicas (PJ) constam 1.148 registros, que somariam 73.622 .597 hectares, valor obviamente incorreto: é quase 20 ve- 
zes maior do que os 4,4 milhões de hectares que o Incra afirmara existirem em 2012. Em duas solicitações de esclarecimentos encaminhadas ao Incra pelo jornalista Lucio Vaz, o órgão federal identificou alguns erros, como, por exemplo, uma fazenda no município de Nova Olímpia (MT), com 9,1 milhões de hectares, o que corresponde a mais 60 vezes a área do próprio município. Após as correções, o Incra apresentou uma nova tabela, com um total de 2,4 milhões de hectares, sendo apenas $502 \mathrm{mil}$ hectares pertencentes a pessoas jurídicas. Ou seja, dois milhões de hectares a menos do que a quantidade apresentada a Sauer e Leite em 2012. É interessante que em 2017 uma reportagem da Confederação Nacional da Agricultura (CONFEDERAÇÃO NACIONAL DA AGRICULTURA, 2017), citando como fonte o Incra e o Serviço Florestal Brasileiro (SFB), apontou haver 2,8 milhões de hectares em mãos de estrangeiros - corroborando os números atuais do Incra.

Os novos dados do Incra, embora incompletos, permitem visualizar uma grande quantidade de propriedades rurais pertencentes a pessoas físicas, que seriam os detentores de aproximadamente $80 \%$ das terras nas mãos de estrangeiros no Brasil. Entre os $20 \%$ restantes, que seriam de pessoas jurídicas, os estados com maiores números de registros seriam Minas Gerais (168), Rio Grande do Sul (152), Santa Catarina (145), Paraná (127) e São Paulo (93). Os dados de PJ estrangeiras são mais consistentes para os estados do Sudeste, Sul e para o Mato Grosso do Sul, onde é possível analisar a destinação do uso da terra. Em MG, PR e SC aproximadamente $75 \%$ das terras de empresas estrangeiras são destinadas ao reflorestamento. No RS o reflorestamento ocorreria em $40 \%$ das propriedades, e, no MS, em 36\% delas. Em SP prevalece a agricultura (cana), em $54 \%$ das propriedades. É notável a falta de dados relativos aos estados da Amazônia, para os quais se constata erros evidentes.

Alguns autores apontam que as falhas no cadastro do Incra, em parte, são reflexo de que o mesmo é auto declaratório, não havendo interesse dos proprietários PF e PJ de revelar informações sobre suas propriedades. Uma análise sobe a regulamentação do Incra, no entanto, mostra que as incompletudes do cadastro rural não significam que o órgão público não tenha conhecimento da estrutura da propriedade da terra. Isso porque, conforme legislação federal, e regulamentos do próprio Incra (2017), a aquisição de imóveis rurais por estrangeiros depende de autorização do presidente do órgão, após aprovação do Conselho Diretor da Autarquia na maior parte dos casos das transações de terras. Para definir critérios, o Incra utiliza o conceito de Módulos de Exploração Indefinida (MEI), que é uma unidade de medida, expressa em hectares, e que varia de acordo com a classificação de cada município em função do que se chama Zona Típica de Módulo (ZTM).

Segundo o Incra (2014), o Modulo de Exploração Indefinida é calculado a partir do módulo rural, outra unidade de medida - esta derivada do conceito de propriedade familiar. O módulo rural procura refletir a interdependência entre três fatores associados ao uso econômico da terra: sua dimensão; sua posição geográfica; bem como a forma e as condições de seu aproveitamento econômico. Como esses fatores se alteram entre regiões, cada município brasileiro possui um valor de 
módulo rural; assim, cada município também tem seu MEI. Pela lógica, nos municípios nos quais ocorre uso mais intenso da terra e há melhor infraestrutura deve haver um MEI de menor valor. Em Passo Fundo (RS), por exemplo, um MEI equivale a 10 hectares; em Guaxupé (MG) ele é de 15 hectares, em Balsas (MA) 30 hectares; e em São Félix do Xingu (PA) o MEI é de 55 hectares.

Há critérios diferentes para pessoas físicas e jurídicas. Segundo o Colégio Notarial do Brasil (RODRIGUES, 2016), entidade de classe que congrega os tabeliães do país, no caso de pessoa natural estrangeira (PF) não será necessária autorização do Incra para aquisição de terras se a mesma possuir apenas um imóvel e o mesmo tiver até três MEI (art. $7^{\circ}$, $\S 1^{\circ}$, Decreto $\left.74.965 / 74\right)$ (BRASIL, 1974). Se a propriedade rural tiver entre três e $20 \mathrm{MEI}$, será necessária autorização do Incra (art. $7^{\circ}$, $2^{\circ}$, Decreto 74.965/74). Para imóveis de área maior, entre 20 e 50 MEI, os estrangeiros pessoas físicas devem obter autorização do Incra e aprovação de um projeto de exploração da área rural (art. $3^{\circ}$, Lei 5.709/71). Acima de 50 MEI, a pessoa natural estrangeira necessita de autorização do presidente da República, ouvido o Conselho de Segurança Nacional (art. $7^{\circ}, \S 5^{\circ}$, Decreto 74.965/74) ou autorização do Congresso Nacional (art. 23, $\S 2^{\circ}$, da Lei 8.629/93), dependendo da localização do imóvel (BRASIL, 1993).

Para as pessoas jurídicas estrangeiras (PJ), ou brasileiras com maioria de capital estrangeiro, as restrições são maiores. Para imóveis de área até $100 \mathrm{MEI}$, o mesmo deverá ter projeto de exploração que faça previsão de uso em ações agrícolas, pecuárias, industriais ou de colonização, que estejam associados aos objetivos estatutários da pessoa jurídica (art. $5^{\circ}$, Lei 5.709/71) (BRASIL, 1971), e deve obter aprovação da pasta da Agricultura e dos órgãos responsáveis pelas atividades a serem desenvolvidas (art. $5^{\circ}$, $1^{\circ}$, Lei 5.709/71, Incra IN 76/2013), incluído o ministério relativo à indústria, no caso de o projeto de uso da área rural ter caráter industrial. No caso de um imóvel de grandes proporções, maior do que $100 \mathrm{MEI}$, a pessoa jurídica estrangeira deve obter autorização do Congresso Nacional (art. 23, $\S 2^{\circ}$, da Lei 8.629/93 e art. $6^{\circ}$, $\S 1^{\circ}$; Incra IN 76/2013).

Adicionalmente, a soma das áreas rurais pertencentes a pessoas estrangeiras, quer sejam físicas ou jurídicas, não pode ultrapassar uma quarta parte (25\%) da superfície do município onde se situem; sendo que pessoas da mesma nacionalidade não poderão ser proprietárias, em cada Município, de mais de $40 \%$ (quarenta por cento) do limite de $25 \%$ da superfície do município (art. $12^{\circ}$, Lei 5.709/71). É vetada a PF e PJ estrangeiras a aquisição de imóveis rurais em áreas de fronteira, salvo se aprovada pelo Conselho de Segurança Nacional (art. 2º V, da Lei 6.634/79) (BRASIL, 1974).

Dessa forma, parece contraditória a falta de informações sobre a real dimensão de estrangeiros pessoas físicas e jurídicas que são proprietários de terras no Brasil: o cadastro rural pode ser auto declaratório e incompleto, mas, por lei, o Incra deve ter, possivelmente em alguma outra base de dados, informações sobre terras pertencentes a estrangeiros. A falta de dados abertos ao público chama a atenção em função da intenção manifestada pelo governo Michel Temer e por parlamentares, amplamente noticiada, de liberar a compra e o arrendamento de terras por estrangeiros. Em 15 de fevereiro de 2017 o então ministro da Fazenda, Henrique Mei- 
relles, afirmou que o governo pretendia, no prazo de um mês e por meio de medida provisória, liberar a venda de terras a estrangeiros (TRUFFI, 2017), fato que não ocorreu até o final de janeiro de 2018.

A iniciativa do Planalto visa dar novo tratamento ao Projeto de Lei 4059/2012, elaborado pela Comissão de Agricultura, Pecuária, Abastecimento e Desenvolvimento Rural da Câmara dos Deputados, que retira restrições à venda de terras a investidores privados internacionais $(\mathrm{CO}$ MISSÃO DE AGRICULTURA, PECUÁRIA, ABASTECIMENTO E DESENVOLVIMENTO RURAL, 2012). O intuito é flexibilizar as regulações impostas durante o governo de Luiz Inácio Lula da Silva (2003-2011) por meio de parecer da Advocacia Geral da União (AGU) que limitou a venda de terras brasileiras a estrangeiros ou empresas brasileiras controladas por estrangeiros, alterando a lei n ${ }^{\circ} 5.709 / 71$ e tornando-a mais restritiva. (BRASIL, 2010). O parecer da AGU estabeleceu que as compras de terras devem ser registradas em livros especiais nos cartórios de imóveis, e que os registros de aquisições feitas por empresas brasileiras controladas por estrangeiros devem ser comunicados trimestralmente à Corregedoria de Justiça dos Estados e ao então existente Ministério do Desenvolvimento Agrário (MDA). O parecer também estabeleceu que empresas só podem adquirir imóveis rurais destinados à implantação de projetos agrícolas, pecuários e industriais que estejam vinculados aos seus objetivos de negócio previstos em estatuto, e que a área dos mesmos não pode exceder $50 \mathrm{MEI}$, devendo tais projetos serem aprovados pelo MDA. As terras adquiridas por estrangeiros ou pertencentes a empresas por eles controladas não pode ultrapassar 25 por cento da superfície do município.

Prevendo flexibilizar esses limites, o deputado federal Newton Cardoso Jr. (PMDB/RJ) afirmou que a aprovação da nova lei poderia gerar investimentos estrangeiros no Brasil "da ordem de $\mathrm{R} \$ 150$ bilhões, ou mais” (CONFEDERAÇÃO NACIONAL DA AGRICULTURA, 2017). Um dos pontos em discussão é o tamanho da área que cada investidor estrangeiro poderia comprar, sendo a proposta inicial de $100 \mathrm{mil}$ hectares de compra e mais 100 mil de arrendamento; posteriormente, a Casa Civil da Presidência da República no governo Temer defendeu não haver limite de área para compra e arrendamento por estrangeiros. O ministro da Agricultura, Pecuária e Abastecimento (Mapa), Blairo Maggi, um dos principais produtores de soja no mundo, manifestou-se favorável à medida, mas pediu restrições para as culturas anuais, como a soja (CONFEDERAÇÃO NACIONAL DA AGRICULTURA, 2017). A argumentação do ministro é a de que investidores estrangeiros poderiam entrar e sair de atividades produtivas de ciclo curto, conforme a rentabilidade das mesmas, afetando sobremaneira as cadeias à montante e à jusante da unidade de produção rural.

Assim, o debate sobre internacionalização de terras no Brasil insere-se em um contexto de grande concentração da propriedade rural, e em um ambiente de falta de transparência nas informações colocadas à disposição da sociedade pelos órgãos públicos. O fato é que o exame da legislação mostra que tal incompletude não é, exatamente, resultado de falta de auto declaração, posto que o Incra, por lei, deve receber essas informações para todas as propriedades de pessoas jurídicas, e para aquelas 
de pessoas físicas de tamanho superior a três MEI, e que os cartórios devem manter registro. Se o Instituto cumpre a legislação que no presente rege a propriedade de terras por estrangeiros, ele deve obrigatoriamente ter controle sobre tais propriedades, talvez em alguma outra base de dados, ainda que o cadastro rural, auto declaratório, esteja incompleto.

Condições para a internacionalização de terras: preço, acesso e produtividade

A proposta brasileira de facilitar a venda de terras a estrangeiros por meio do Projeto de Lei 4059/2012 enquadra-se na discussão conhecida como corrida mundial por terras, "estrangeirização" ou land grabbing. Bastante explorada na literatura sobre economia política da segurança e soberania alimentar e nutricional (BELLO, 2012; MAGDOFF; TOKAR, 2010; McMICHAEL, 2010), a compra de terras em terceiros países por empresas privadas, governos, ou associação entre ambos, tem chamado a atenção especialmente nos últimos dez anos, mas não se trata de um fenômeno novo.

A disputa por terras sempre esteve ligada à história de migrações humanas, acompanhada pela transferência de espécies vegetais e animais naquilo que Crosby (1986) chama de formação de "neo-europas": assentamentos que buscam reproduzir a paisagem, costumes e formas de produção dos sítios originais dos povos. $\mathrm{O}$ aspecto particular do período recente de busca por terras estrangeiras é a amplitude deste processo, suas dinâmicas e suas correlações, que refletem o modelo neoliberal baseado na "mitologia" dos benefícios e uma "livre" circulação de mercadorias e recursos financeiros (SCREPANTI, 2014). Com maior liberdade em relação a amarras regulatórias a partir do início da década de 1970 (GILPIN, 2002), a circulação de bens e serviços levou à "mundialização" do capital (CHESNAIS, 2010), que passou a buscar alternativas de maximização de ganho rentista, até que a crise das hipotecas nos Estados Unidos deflagrou efeitos sistêmicos na economia mundial atingindo, desde então, o mercado agroalimentar de forma ampla (CLAPP; HELLEINER, 2010).

Em termos breves, esse processo de financeirização "acabou por amalgamar os mercados acionário, cambial, imobiliário, commodities etc. em torno de expectativas convergentes de ganho, e por contagiar negativamente do lado real da economia”, afirmam Paula, Santos e Pereira (2015), para quem "simultaneamente a essas mudanças o sistema agroalimentar ganhou dimensões globais na esteira de intensas mudanças tecnológicas e de internacionalização do capital agroindustrial e do padrão de consumo".

Os efeitos no sistema agroalimentar causados pela financeirização das operações ligadas a todas as etapas da cadeia de produção de alimentos - da terra à prateleira do supermercado - se constituíram em um dos principais fatores a desencadear a crise alimentar de 2007/08, com a elevação dos preços dos alimentos nos mercados mundiais, e um aumento da volatilidade de preços desde então. Adicione-se à dimensão financeira a convergência de problemas derivados de mudanças climáticas (BEDDINGTON et al., 2012) expansão da produção de agro-combustíveis 
(HOUTART, 2010) em conjunto com a questão energética, e necessidade de acesso à água.

Investimentos de capital em fundos financeiros ligados a commodities cresceram de forma rápida, atraindo montantes bastante elevados e que deixaram de encontrar segurança e taxas de retorno em produtos financeiros que tradicionalmente investiam. Ao mesmo tempo em que a crise alimentar elevou ainda que temporariamente os preços dos alimentos, algumas tendências mutuamente reforçadoras criaram condições para investimentos internacionais em terras. Escrevendo para a Organização das Nações Unidas para a Alimentação e a Agricultura (FAO), Borras Júnior et al. (2011) identificam quatro "categorias amplas", que formaram as condições que tornaram propícia tal corrida por terras:

- demanda crescente por alimentos, ração e combustível, envolvendo a destinação de grandes áreas para a produção de rebanho bovino, soja, cana-de-açúcar de óleo de palma;

- aumento da demanda por minerais e produtos de madeira pelas indústrias extrativas;

- crescimento da destinação de áreas para conservação ambiental, em função da necessidade de retenção de carbono e de manejo de áreas para a redução do desmatamento; e

- necessidade de o capital financeiro mundializado e rentista encontrar "âncoras" por meio da aplicação em ativos reais como a terra.

Esse processo, apontam os autores, possui diversas facetas, o que torna a sua definição algo contencioso e difícil. Por isso, Borras Júnior et al. (2011) evitam uma definição dessas "aquisições de terras em larga escala", ou "grandes investimentos na compra de terras", e preferem arrolar dez características das mesmas, sendo que a principal delas é que se trata de "aquisições de grandes extensões de terra por meio de compra ou arrendamento", e destinados à produção ou ao arrendamento, com o propósito de obter produtos ou acessar água e bens florestais, direta ou indiretamente, por meio de produtos alimentares ou não, para comércio interno e consumo ou para exportação, podendo, inclusive, se constituir em uma atividade que visa ser apenas a captura de lucro por meio da cadeia de valor. Esse processo de land grabbing pode envolver investidores privados e/ou públicos, domésticos ou estrangeiros, ter consequências sociais e ambientais diversas, e cujos investimentos estejam alinhadas com o caráter e a dinâmica do desenvolvimento neoliberal, alinhados com a lógica das mudanças políticas globais, tais quais os biocombustíveis, as grandes iniciativas de conservação, e a crise financeira.

A quantidade de terras passíveis de serem adquiridas em terceiros países por investidores internacionais é incerta. Adicionalmente, não são apenas os países mais industrializados os responsáveis pela compra de terras, e as aquisições não são apenas nos países do Sul Global. Estudo preparado para o Banco Mundial (FISHER; SHAH, 2010) identificou 445 milhões de hectares no mundo que estariam "disponíveis" para investimentos. Seriam terras sem cobertura florestal, não consideradas como sendo áreas de conservação da biodiversidade, e com densidade populacional de, no máximo, 25 habitantes por quilômetro quadrado - con- 
dições que possibilitariam investimentos em plantações em larga escala com menor custo ambiental e social.

Os três países com maior área de terras "disponíveis" no mundo seriam, por ordem, Brasil, Federação Russa e República Democrática do Congo. No caso brasileiro, os autores identificaram 45,5 milhões de hectares que poderiam receber investimentos estrangeiros, uma área equivalente a quase duas vezes o tamanho do estado de São Paulo. Considerando que os investimentos estrangeiros não seriam apenas na compra de terras, mas também em infraestrutura, máquinas, equipamentos, sementes, mudas, agrotóxicos etc., o valor de R $\$ 150$ bilhões que fora previsto pelo deputado Cardoso Jr. não é exorbitante para esse tamanho de área passível de venda.

A conceituação de terras como "vazias", "subutilizadas" ou "marginais" tem sido amplamente criticado, pois invariavelmente refere-se a terras nas quais habitam camponeses e/ou povos indígenas, ou outros povos e comunidades tradicionais, que podem possuir direitos territoriais, muitas vezes ancestrais, e têm seus modos de vida diferenciados. Suas práticas produtivas, e de relação com o ambiente, invariavelmente não estão subordinadas à lógica de mercado, e não deveriam ser enquadradas nas categorias "vazias", "subutilizadas" ou "marginais".

O preço da terra é fator determinante na agricultura, posto que se trata de ativo imobilizado de longo prazo, e que demanda grande quantidade (extensão territorial) para que a produção ganhe escala, especialmente no caso da agricultura intensiva em capital. Segundo Bacha, Stebs e Harbs (2016), nos principais países agrícolas o preço da terra tem aumentado de maneira contínua desde 1999. No Brasil, afirmam, o maior preço da terra para lavoura está no Sul $(\mathrm{R} \$ 21.555,47 /$ ha em 2013 , a preços de dezembro de 2015); já no Sudeste e Centro-Oeste os preços são próximos entre si - R \$ 12.224,19/ha e R\$12.764,40/ha, respectivamente -; seguidos do preço da terra no Nordeste, $\mathrm{R} \$ 5.222,04 / \mathrm{ha}$, e, por fim, do Norte, o menor valor: R\$3.373,18/ha. Gasques et al. (2008) calcularam que o preço médio da terra no Brasil valeria aproximadamente $34,7 \%$ do preço médio da terra para lavouras nos Estados Unidos.

Estudo do Ministério da Agricultura, Pecuária e Abastecimento (Mapa) em 2015 apontou que ocorreu no Brasil uma valorização média das terras de $308 \%$ entre 2002 e 2013 , para uma inflação de $121,9 \%$ no mesmo período, pelo IGP-DI da Fundação Getúlio Vargas (FGV). No Tocantins e em outras regiões, a variação chegou a quase $700 \%$. Segundo o estudo, no Brasil a terra representa $70,5 \%$ do valor dos bens existentes nos estabelecimentos agropecuários, o que confirma a percepção de que existem poucos prédios, instalações, benfeitorias, veículos, implementos etc. (PORTAL BRASIL, 2015). Esse cenário parece contribuir para a atual redução nas vendas de terras (LIMA FILHO; AGUIAR; TORRES, 2016).

No contexto de preços elevados para as propriedades rurais no Brasil, a proposta de facilitação da compra para o capital internacional se justifica como estratégia dupla. De um lado, a oferta de terras em grandes proporções pode levar à redução do preço médio, destravando o mercado. De outro lado, e de forma complementar, possibilita um reordenamento produtivo no território. Investidores internacionais terão preferência por terras 
onde há maior presença de infraestrutura e maior segurança de direitos de propriedade. São as terras mais caras e já ocupadas, mas que ainda têm margem de valorização. Um proprietário poderá vender mais facilmente a terra nessas condições se lhe for possível transferir-se para outra localidade, eventualmente alterando sua produção rural. Eventualmente, como alternativa, ele pode abandonar a produção rural e obter renda por meio de aplicação financeira da verba auferida na venda da terra.

Assim, a falta de informações sobre a propriedade rural no Brasil parece não ser um problema, mas sim uma oportunidade. Aqueles que têm acesso à informação privilegiada sobre esses diversos usos da terra realizam transações igualmente privilegiadas. A empresa AGBI, por exemplo, é uma gestora de ativos reais e anuncia ter participado da aquisição e gestão de mais de 200.000 hectares de terras no Brasil - mas não informa a localização de quaisquer delas. A empresa é comandada pelo empresário Luciano Lewandowski, que também participa de outra empresa, a Global Logistics Properties, uma das maiores do mundo em ativos imobiliários, com um portfólio da ordem de US\$ 28 bilhões. No caso desses investimentos, situados em áreas urbanas, diversas localidades onde os negócios foram fechados são mencionadas.

Do ponto de vista de ganhos financeiros, o valor pago pela terra é importante, mas deve ser analisado à luz de custos e rendimentos. A estrutura de incentivos fiscais e financeiros aplicáveis à terra possui grande variação entre países, e dentro dos países, assim como há também grande variação nas possibilidades de obtenção outras rendas e benefícios. $\mathrm{O}$ conjunto de incentivos à propriedade de terra é amplo, e varia de pessoas físicas para jurídicas. Proprietários pessoa física buscam prioritariamente retornos financeiros, mas também outros retornos cujos interesses são mais atinentes à lógica de prestígio das elites: buscam motivações materiais, práticas, existenciais e também espirituais (GEISLER, 2015); ou, conforme Linklater (2013, apud GEISLER, 2015) a elite busca diversificação da carteira de investimentos, fama, status e às vezes um legado baseado em locais para seus herdeiros. Investidores corporativos, pessoas jurídicas, por sua vez, tendem à impessoalidade em seu crivo e olham para possibilidades de acumulação por valorização imobiliária e vantagens fiscais. Dada a atual volatilidade dos mercados, e o caráter nômade e imaterial de investimentos financeiros, a compra de terras também se relaciona à busca de alguma ancoragem em ativos reais (LINKLATER, 2013, apud GEISLER, 2015).

Do ponto de vista da produção de bens e do usufruto de serviços providos pela terra e pela natureza, os negócios rurais são mais atrativos quando propiciam usos múltiplos. É, por exemplo, o caso de regiões onde uma rede de cidades torna a terra atraente para diversos usos - incluindo agricultura, turismo, caça e pesca, conservação ambiental, residência, logística, e fábricas, entre outras possíveis aplicações - uma estratégia que recebe o nome em Inglês de HBU ("higher and better use"), que pode ser compreendido como usos melhorados e nobres, em tradução livre. Em um caso de internacionalização de terras "reversa", por exemplo, o banco BTG Pactual adquiriu 422,7 mil hectares nos Estados Unidos; 50,6 mil ha na África do Sul; 28,7 mil ha no Uruguai; 6,6 mil ha Guatemala; 8,4 mil 
ha Estônia; 3,7 mil ha Hungria; além de 192,4 mil ha no Brasil. No caso dos Estados Unidos, por meio de sua subsidiária Timberland Investment Group (TIG), o BTG Pactual destina aproximadamente 280 mil hectares a uma atividade que talvez o setor empresarial qualifique como HBU: mais de mil licenças de caça (BTGPACTUAL, 2015). Realizada em propriedades que invariavelmente são prioritariamente destinadas a plantações florestais, a caça de animais como "uso múltiplo" do estabelecimento rural mostra como são diversas as possibilidades de renda.

Busca por terras, agricultura e madeira: usos múltiplos e usos flexíveis . .

O Brasil deve chegar em 2024 como o maior produtor mundial de alimentos. A estimativa é da Organização para a Cooperação e Desenvolvimento Econômico (OCDE) e da FAO, no relatório "Perspectivas Agrícolas: desafios para a agricultura brasileira 2015-2024", que vê na expansão territorial a principal fonte do aumento da produção agrícola. Entre 1990 e 2012 foram incorporados 34 milhões de hectares, o que seria uma das maiores expansões de uso da terra em escala global. Subsequentemente, nas safras 2000/01 e 20003/04 foram adicionados mais nove milhões de hectares, sendo metade destinada à soja, que impulsiona consigo as culturas de milho de segunda safra e algodão (ORGANIZAÇÃO DAS NACÕES UNIDAS PARA ALIMENTAÇÃO E AGRICULTURA, 2015). Em larga medida, as terras adicionadas à produção estão localizadas na região denominada Amazônia Legal, e foram responsáveis pelo desmatamento, a maior parte sem autorização dos órgãos públicos responsáveis, de áreas originalmente vegetadas com cerrado e/ou florestas.

Até 2024 o uso da terra deverá ocupar 69,4 milhões de hectares no Brasil, o que corresponde a um incremento de $20 \%$ sobre a área média utilizada entre 2012 e 2014. O destaque é para um aumento previsto de $35 \%$ na área destinada à cana-de-açúcar, e de $23 \%$ para as oleaginosas, segundo a ORGANIZAÇÃO DAS NACÕES UNIDAS PARA ALIMENTAÇÃO E AGRICULTURA (2015), para quem as oleaginosas devem continuar a manter o domínio do uso da terra no país, e que a soja irá responder por praticamente metade de todo cultivo adicional em 2024 (ORGANIZAÇÃO DAS NACÕES UNIDAS PARA ALIMENTAÇÃO E AGRICULTURA, 2015).

Esses produtos coincidem com aqueles identificados por Borras Júnior et al. (2014) como sendo os que têm tido grande aceleração no plantio em todo o mundo: cana-de-açúcar, soja, óleo de palma, milho, girassol, mandioca, beterraba, coco e árvores de rápido crescimento. O que essas plantas têm em comum é o que se chama "multiple-ness", ou usos múltiplos, e "flexible-ness", ou usos flexíveis. O coco serve de exemplo para os dois conceitos. Ele possui vários usos múltiplos, como água, óleo, cosméticos, tecidos e biodiesel. Mas possui baixa flexibilidade: a indústria que dele retira um produto (água, por exemplo), não tem capacidade de produzir biodiesel. Flexível é a commodity que permite a uma mesma unidade produtiva, com poucos incrementos em maquinário e tecnologia, alterar a sua produção de acordo com demandas de mercado. 
As culturas de uso múltiplo e flexível são extremamente atraentes para a agricultura capitalista não apenas pela possibilidade de adaptação às variações de mercado, mas também porque são mais atraentes ao capital financeiro dado o baixo grau de risco que representam, e porque geram uma nova narrativa de desenvolvimento (BORRAS JÚNIOR. et. al., 2016). Adicionalmente, tais culturas de uso múltiplo e flexível estão associadas de forma mais direta e próxima ao capital industrial, possibilitando ganhos de escala e maior controle de mercados, além de um ambiente institucional corporativo que se afasta da lógica econômica e das práticas políticas das tradicionais elites rurais - agregando estabilidade institucional. Esses usos múltiplos incluem serviços (como a caça), e o uso alimentar, porém a maior margem de lucro pode estar em outros usos industriais do mesmo bem agrícola, especialmente aqueles que tenham maior valor agregado.

A maior parte da pesquisa sobre land grabbing tem sido "agro-cêntrica" (EDELMAN, 2016), e tem permanecido à margem dos estudos sobre outras formas de controle de terras relacionadas a vários tipos de fins não agrícolas, tais como "madeira, mineração, recursos de energia (tanto de petróleo e parques eólicos), água, especulação, urbanização, construção de parques industriais e outras infraestruturas (estradas, aeroportos, etc.)", diz Edelman (2016, p. 11), para quem importa, também, "a consolidação das cadeias de valor, proteção de zonas ecológicas, ecoturismo e investimentos em sumidouros de carbono ou outras fontes de pagamentos por serviços ambientais" (EDELMAN, 2016, p. 11).

O caso da produção de madeira tem recebido pouca atenção nas discussões de land grabbing, apesar da forte expansão de florestas plantadas: entre 1990 e 2010 elas cresceram 48\% no mundo; 67\% na América do Sul; $560,5 \%$ no Canadá; e $815,1 \%$ no México. É uma expansão internacional superior a cinco milhões de hectares por ano (KRÖGER, 2014). Adicionalmente, chama a atenção o fato de que os dados do Incra, apesar de imprecisos, são mais completos para os estados do sudeste e sul do Brasil, nos quais a maior parte das terras pertencentes a estrangeiros está ocupada com plantações de madeira: primeiramente eucalipto e, em segundo lugar, pinus.

Note-se que o conceito de "floresta" não corresponde, exatamente, à percepção do não especialista: na verdade, a "Avaliação Global de Florestas", da FAO, compreende como "florestas" as formações de árvores que tenham, ao menos, cinco metros de altura, $10 \%$ de cobertura de dossel, e meio hectare de área (HIGH LEVEL PANEL OF EXPERTS, 2017). Essa definição é seguida pelo Serviço Florestal Brasileiro (SFB), que reconhece haver em território nacional doze tipos de formações florestais, além da categoria reflorestamento (SFB, 2017).

Em 2014 foi criada uma associação denominada Indústria Brasileira de Árvores (IBÁ), como resultado da união Associação Brasileira da Indústria de Painéis de Madeira (ABIPA), da Associação Brasileira da Indústria de Piso Laminado de Alta Resistência (ABIPLAR), da Associação Brasileira dos Produtores de Florestas Plantadas (ABRAF) e da Associação Brasileira de Celulose e Papel (BRACELPA). Em 2015, a presidente dessa entidade, Elizabeth de Carvalhaes, assumiu a presidência do Internatio- 
nal Council of Forest and Paper Associations (ICFPA), a principal entidade do setor de base florestal no mundo. A Ibá (2014) estima que o abastecimento global de madeira irá demandar mais 250 milhões de hectares de florestas plantadas até 2050 , devido ao aumento da população, que deve atingir nove bilhões em 2030, e do consumo de energia de biomassa, que para a entidade deve dobrar até 2050.

A América Latina e o Caribe deverão ser os maiores provedores mundiais de madeira, com área plantada menor do que em outras regiões (federação Russa e China, por exemplo), mas com a maior produtividade do mundo (INDÚSTRIA BRASILEIRA DE ÁRVORES, 2015). De fato, o Brasil se destaca por ser o campeão mundial de produtividade na indústria de base florestal: "a área florestal necessária para a produção de 1,5 milhão de toneladas de celulose por ano (no Brasil) é de 140 mil hectares, um quinto da área necessária na Escandinávia” (INDÚSTRIA BRASILEIRA DE ÁRVORES, 2015). No caso da celulose, a demanda mundial deve dobrar até 2050, em relação ao consumo de 2005 (HIGH LEVEL PANEL OF EXPERTS, 2017).

O crescimento da demanda reflete, também, um grande alargamento nas possibilidades de emprego da madeira, dado que novas tecnologias possibilitam mais usos múltiplos e usos flexíveis do que culturas alimentares (KRÖGER, 2014), podendo, inclusive, ser utilizada na alimentação e na fabricação de cosméticos e fármacos, além de centenas de produtos e ter, também, função ambiental. Não sem controvérsia, discute-se, por exemplo, os serviços ambientais de florestas plantadas: há divergências se elas podem contar como estoques de carbono (pelo fato de serem cortadas em poucos anos), e quais seus impactos na biodiversidade, na conservação do solo, na demanda por água, na dispersão de sementes, e outras funções, além do fato de que a transformação industrial da madeira em papel e celulose, ou sua queima na forma de carvão, resultam em emissões que fariam com que as plantações de árvores fossem, na verdade, emissoras de carbono, e não sumidouros de carbono (OVERBEEK; KRÖGER; GERBER, 2012). A representação do setor argumenta que, em comparação com fontes de combustíveis fósseis, as emissões de carbono das florestas plantadas são menores (INDÚSTRIA BRASILEIRA DE ÁRVORES, 2015).

O debate sobre sustentabilidade se une a interesses capitalistas do setor florestal em diversas frentes. Uma delas, em estágio já avançado no Brasil, é a integração entre lavoura, pecuária e floresta (ILPF). Trata-se de diferentes formas de combinação desses três usos na formação de mosaicos, que podem ser arranjos de lavoura-pecuária (agropastoril); lavoura-floresta (silviagrícola); pecuária-floresta (silvipastoril) e lavoura-pecuária-floresta (agrossilvipastoril). Embora representativos para a plantação de árvores, esses mosaicos não são considerados pela FAO como florestas, mas sim como sistemas agrícolas agroflorestais (HIGH LEVEL PANEL OF EXPERTS, 2017).

No entanto parece óbvio que um produtor não irá plantar madeira se não puder vendê-la. Segundo a Embrapa (2016), na safra 2015/2016 havia 11,5 milhões de hectares em ILPF no Brasil, com destaques para os estados de Mato Grosso do Sul (18\% do total de ILPF no país), Mato Gros- 
so (13\%), Rio Grande do Sul (13\%), e Minas Gerais (9\%) - justamente nas localidades nas quais há proximidade com unidades industriais de papel e celulose e com carvoarias. Ou seja, a demanda por madeira se alastra e possibilita o uso múltiplo da terra no país. Interessante que a área com ILPF é maior do que a área com florestas plantadas, que, em 2015, somam cerca de 7,8 milhões de hectares, conforme a Ibá (2016), e 9,9 milhões de hectares segundo o IBGE.

O Brasil tem uma posição particularmente favorável a plantações de madeira, dada sua grande produtividade - tanto para a produção de carvão como para finalidades industriais. As plantações destinadas a carvão para abastecimento de fornos produtores de ferro-gusa estão localizadas em Minas Gerais e Norte do país (Maranhão, Pará e Piauí). Embora tais empreendimentos possam constituir atrativo para a internacionalização, o fato de estarem localizados no bioma Amazônia, a falta de direitos de propriedade claros sobre a terra nessa região, conflitos agrários com camponeses, agricultores familiares, povos tradicionais e indígenas, além de custos de transação mais elevados por deficiências em infraestrutura, afastam investidores estrangeiros desse mercado, posto que eles temem riscos financeiros e os riscos ligados à reputação, ou riscos de "branding", como a exposição da marca empresarial em âmbito internacional (DAUVERGNE; LISTER, 2011). O capital internacional requer, ao menos, uma boa aparência, "civilizada".

Ademais, fábricas de papel e celulose pagam mais pela madeira de produtores autônomos do que as gusarias, que enfrentam maiores oscilações de demanda e preços, especialmente quando o carvão se torna úmido no instável clima amazônico. O mercado de plantações industriais é mais atrativo, estável e previsível: possui competitividade internacional, e abastece o setor de papel e celulose brasileiro, que caminha para a liderança mundial. A Fibria, empresa brasileira pertencente ao grupo Votarantim S.A. (29,42\%) e ao BNDESPar (29,08\%) já é a líder mundial na produção de celulose branqueada de eucalipto, tendo custos de fabricação 57\% menores do que a média mundial (DAUVERGNE; LISTER, 2011a), e dificilmente deixará de sê-lo. Segundo o departamento de Pesquisas e Estudos Econômicos do Bradesco (2017), o custo de produção de celulose no Brasil é de US\$235 por tonelada, enquanto que nos Estados Unidos o custo é de US\$ 420, e, na China, de US\$ 498. A Ibá acredita que em 2017 o Brasil passará de quarto ao segundo lugar na produção mundial de celulose, ultrapassando Canadá e China de uma só vez, restando à frente os Estados Unidos. Papel e celulose respondem atualmente por $4,1 \%$ da pauta total de exportações do Brasil, percentual ainda bem menor do que o complexo soja $(13,0 \%)$, e menor do que o complexo carnes $(7,6 \%)$, e o de açúcar e etanol $(5,2 \%)$, porém superior aos 3,4\% do café (BRADESCO, 2017).

Se as perspectivas para o setor de papel de celulose são boas e sugerem aumento de plantações, do ponto de vista de novos mercados e, provavelmente de valor agregado, a principal perspectiva econômica se encontra naquilo que se chama bioeconomia: a junção de novas tecnologias produtoras de biocombustíveis, bioprodutos e bioprocessos. "A biologia está se tornando um poderoso vetor de dinamismo da econo- 
mia mundial, como base da inovação no século XXI”, afirma o Centro de Gestão e Estudos Estratégicos (QUÍMICA..., 2010; entidade vinculada ao Ministério da Ciência, Tecnologia e Inovação). Segundo Erikson, Nelson e Winters (2012), os produtos de base biológica são classificados em três categorias: produtos químicos de commodities; especialidades químicas; e materiais. Juntas, representam uma oportunidade para substituição de produtos petroquímicos já no curto prazo. Dentre novos usos de produtos de base florestal, a Ibá (2014) destaca seis: bioplásticos, etanol, nanofibras, bio-óleos, "tall oil" (subproduto da fabricação da celulose de fibra longa), e lignina (cuja aplicação vai da alimentação humana à perfuração de poços de petróleo, metalurgia, adesivos e diversas outras aplicações de alto valor agregado). Além dos usos dos troncos de madeira, há outras centenas de aplicações, que incluem produtos das flores, folhas, frutos, galhos, casca e resina.

Esses novos usos estão em implantação nas empresas de base florestal instaladas no hemisfério Norte, que buscam agregar valor à sua base florestal, posto que o valor da commodity madeira desses países já não tem como competir com o Brasil e outros países da América Latina (Chile e Uruguai), tanto em papel e celulose, como em outros setores da indústria de base florestal. Tem havido uma "evidente migração da produção do hemisfério Norte para o Sul" (INDÚSTRIA BRASILEIRA DE ÁRVORES, 2016, p. 25), mas o aproveitamento da base florestal para novos produtos se concentra nos países do Norte (Estados Unidos, Canadá, Finlândia, Noruega e Suécia), que desenvolvem uma nova bioeconomia.

A estratégia desses países industrializados tem sido a de "acoplar" biorrefinarias às unidades industriais já existentes e destinadas à produção de papel e celulose ou de etanol visando obter bioeletricidade e novos produtos químicos (a chamada white biotech), entre os quais os bioplásticos. No Brasil, a implementação de biorrefinarias é incipiente, e deve ocorrer tanto "acopladas" como em novas unidades criadas exclusivamente para essa finalidade. Na verdade, as modernas fábricas de papel e celulose que utilizam o processo "kraft" já são biorrefinarias "pelo menos quando se fala da produção de energia elétrica e térmica por meio da utilização de resíduos industriais e florestais que seriam destinados a aterros ou estações de tratamento de efluentes" (NALI, 2016). O desenvolvimento do setor no Brasil é estudado pelo Laboratório Nacional de Ciência e Tecnologia do Bioetanol (CTBE), pelo Ministério da Ciência, Tecnologia e Inovação, pela Associação Brasileira Técnica de Celulose e Papel, pelo BNDES, e por empresas do setor.

Biorrefinarias podem utilizar diversas matérias-primas para a produção, incluindo cana-de-açúcar, algas, lixo, plantas oleaginosas e outras. Nesse sentido, a bioeconomia deverá demandar terras (e águas) para implantação de outras culturas, não apenas de madeira, e deve se espalhar pelo território brasileiro. De fato, o peso elevado das toras faz com que as áreas de reflorestamento sejam estabelecidas em localidades próximas às unidades de processamento de papel e celulose e de painéis reconstituídos, que, no Brasil, estão localizadas nos estados de São Paulo, Paraná, Santa Catarina, Rio Grande do Sul, Mato Grosso do Sul, Bahia, Espírito Santo e Minas Gerais. O que diferencia a madeira de outras culturas que 
podem atrair investidores internacionais é, principalmente, que o investidor no mercado de base florestal busca um controle maior sobre a terra, como se discutirá adiante.

Desde a década de 1960, a modernização conservadora da agricultura brasileira levou a uma forte concentração fundiária, cujos dados foram apresentados na Tabela I. No período recente, estima-se que tal concentração tenha aumentado como resultado da expansão do agronegócio de larga escala, brasileiro e estrangeiro, na produção agrícola, especialmente de oleaginosas. Trata-se de um processo que Oliveira (2016) chama de mundialização da agricultura, e que ocorre por meio de dois processos que o autor denomina como territorialização dos monopólios e de monopolização dos territórios. O primeiro processo refere-se ao controle da propriedade privada da terra, do processo produtivo no campo e do processamento industrial da produção agropecuária. No segundo processo, empresas de comercialização e de processamento industrial, que não produzem no campo, passam a controlar fazendeiros capitalistas, agricultores familiares e camponeses por meio de mecanismos de subordinação.

O setor florestal possibilita os dois modelos de territorialização e monopolização. O ILPF é mais próximo do agronegócio, e, portanto, da monopolização de territórios. Já o plantio florestal industrial seria a expressão da territorialização dos monopólios do setor de papel e celulose. Segundo Kröger (2016), esse setor busca ser proprietário da terra onde planta porque é grande o capital que permanece imobilizado por anos, e porque as plantações industriais de árvores possibilitam redução de riscos, dado que se trata de um bem que possui crescimento biológico, dando concretude a investimentos que, de outra forma, poderiam se beneficiar de margens polpudas de lucratividade nos mercados financeiros internacionais. Ocorre que as plantações são um investimento razoavelmente seguro, mas não rendem muito acima da caderneta de poupança quando, no momento do corte, se descontam os tratos culturais que demandaram capital de giro por vários anos. Ser um plantador autônomo de florestas não é um investimento muito atrativo no mundo rural - faz mais sentido para aqueles que são processadores de madeira e podem incorporar ganhos em todas as etapas do processo.

Há usos múltiplos, porém os mais rentáveis são derivados da madeira (tronco), que tem apenas uma colheita, e não de flores, folhas e galhos, que têm várias. Assim, afirma Kröger, o capital industrial no setor florestal tende a comprar seus ativos e a excluir os detentores da terra. No entanto, no Brasil apenas $34 \%$ dos hectares plantados são pertencentes às empresas de papel e celulose, estima a análise do Bradesco (2017), que trabalha com a área de florestas plantadas informada pelo Ibá. O banco estima que investidores financeiros detenham $10,2 \%$ da área plantada, uma porcentagem que é mencionada por empresas de consultoria como um valor médio em termos globais. Interessante que o Bradesco (2017) considere que o Brasil seja o segundo maior destino dos investidores nesta área, recebendo $29 \%$ dos investimentos, atrás dos Estados Unidos, que recebem $66 \%$ - nomes de investidores e valores não são mencionados. Portanto, os investimentos devem ser recentes, devem estar alterando o mercado, e certamente não estão sendo exibidos 
em estatísticas oficiais. O fato de que muitos reflorestamentos pertencem a autônomos pode ser explicado pela concentração fundiária: ao detentor de muitas terras é interessante ter uma "ancoragem" no estável investimento em madeira caso ocorra uma quebra na sua lavoura. A lógica da estabilidade é o que faz com que a maioria dos investidores internacionais em plantações de madeira sejam fundos de pensão e fundos ligados a universidades norte-americanas.

Investimentos no setor de papel e celulose ocorrem de forma cíclica, em grandes volumes, posto que têm um longo período de maturação. Tradicionalmente, a demanda não cresce na mesma proporção; no entanto, a expansão das economias da China e da Índia têm tido um rebatimento forte na demanda por papel e papelão, em particular para impressão (o chamado papel A4) e para caixas utilizadas no crescente comércio eletrônico. Adicione-se a essas tendências o já mencionado crescimento em combustíveis de biomassa, e novos materiais, especialmente o plástico derivado de madeira. Também se estima que a construção de casas de madeira deve aquecer o mercado, principalmente o de madeira serrada, que no Brasil é maior do que o da celulose em termos de metros cúbicos consumidos (SISTEMA NACIONAL DE INFORMAÇÕES FLORESTAIS, 2017a). Há outras aplicações potenciais que ainda precisam "vingar", como carros de madeira já desenvolvida pela Toyota, e que tendem a ser até $15 \%$ mais leves do que os atuais veículos de metal e plástico.

Além das demandas de mercado de papel e celulose e de novos produtos, tanto a produção agropecuária como a florestal já está sendo modificada pela introdução de organismos geneticamente modificados (OGMs). Em 2016 o Brasil se estabeleceu como o segundo maior usuário no mundo de OGMs (49,1 milhões de hectares plantados, contra 72,92 milhões de hectares nos EUA), ou $27 \%$ da área global de 185,1 milhões de hectares com transgênicos, sendo que entre 2015 e 2016 a área total de cultivo biotecnológico do Brasil aumentou $11 \%$, ou 4,9 milhões de hectares, "de longe o maior aumento em qualquer país do mundo em 2016 " (ISAAA, 2016). No caso de árvores, a Comissão Técnica Nacional de Biossegurança (CTNBIO) deu parecer favorável ( $n^{\circ}$ 4408/2015) à solicitação da empresa FuturaGene do Brasil Tecnologia S.A. para a liberação comercial de eucalipto geneticamente modificado por considerar que "as medidas de biossegurança propostas atendem às normas e à legislação pertinente, que visam garantir a biossegurança do meio ambiente, agricultura, saúde humana e animal" (BRASIL, 2017, p. 2). A perspectiva produtivista da transgenia de eucalipto é que seja reduzido de sete para cinco anos e meio o período de crescimento até o corte para a indústria de papel e celulose, sendo que a árvore transgênica deve ser a ser mais grossa e mais alta do que sua espécie natural.

Considerações finais

Interesses internacionais pela compra de terras brasileiras devem se ligar tanto à agropecuária como também às plantações de madeira. Em alguns casos, essas alternativas são excludentes, mas o crescimento significativo das culturas com modelos ILPF indicam que existe uma so- 
breposição de interesses. As alternativas de especialização em produtos agropecuários e florestais que têm "multiple-ness" e "flexible-ness" devem reger o padrão de investimento na busca por terras, além das demandas já conhecidas de baixo risco e elevado retorno.

Esses dois setores estão em crescimento, e mesmo um pequeno crescimento percentual na agropecuária resultará na incorporação de grandes parcelas de terra, pelo fato de a área sob cultivo já ser muito grande. No entanto, em termos proporcionais, o crescimento de plantações de florestas, especialmente aquelas de finalidade industrial, deve ser maior. Isso porque o Brasil possui produtividade inigualável nas plantações de madeira, especialmente de eucalipto, e possui grandes extensões de terra e disponibilidade hídrica. Fábricas de papel e celulose demandam água em quantidades tão grandes que necessitam captar de rios como Paraná e Tocantins. Uma investigação sobre a relação entre plantações de madeira e a presença de rios ou aquíferos podem dar algumas indicações sobre locais preferidos para a compra de terras.

O valor das terras no Brasil teve grande elevação de preços, mais ainda é atrativo e tem possibilidades de ganhos polpudos. A maior parte das terras ainda tem pouca estrutura produtiva (casas, silos, cercas, aceiros) e acesso à infraestrutura de comunicação e transporte. Uma parte do interesse por terras reside nas possibilidades de ganho pela estruturação da propriedade rural para venda futura. O uso da terra nesse ínterim pode não ser o principal objetivo do investidor. De certa forma, o uso de plantações de madeira guarda essa lógica: a de ser uma reserva de valor para outras finalidades. Adicionalmente, as alegadas funções ambientais das plantações, ainda que contestáveis, agregam valor para alguns investidores.

Fábricas de papel e celulose tendem a ser donas das terras das quais extraem madeira, ou a manter contratos que configuram dimensões de land grabbing por determinar as alternativas de uso. Uma dimensão associada às formas de controle da terra é o fato de que plantações transgênicas de eucalipto de outras espécies levam aos mesmos efeitos de outras culturas de OGMs em termos de impactos ambientais: acabam por contaminar outras produções adjacentes, afetam a biodiversidade, demandam mais água pelo crescimento acelerado, e estruturam mercados locais e regionais de forma a excluir outros produtores posicionados fora da cadeia-OGM.

Nesse contexto, o fato de o mercado de terras ter secretismo não é uma falha do órgão público, não ao menos no que tange ao cadastro de terras. Se o Incra não possui informações sobre as terras pertencentes a estrangeiros é porque não está a cumprir a lei que regula o funcionamento do Instituto. A falta de informações abertas, em qualquer mercado, é funcional para aqueles que conseguem informação por outros meios. Dado que os meios de comunicação têm divulgado compras de parcelas de terras de grande extensão, tal fato sugere que empresas e corretores possuem alguma forma de acesso privilegiado aos dados de terras disponíveis à venda.

Portanto, esses dados do mercado, ainda que esparsos, mas associados aos dados de instituições como o Banco Mundial, e com os dados 
revelados de investimento na agropecuária e no setor florestal, indicam uma forte tendência à internacionalização de terras brasileiras. No caso de florestas plantadas, as possibilidades de uso múltiplo e flexível da commodity aumentam o interesse do capital pela terra. A produção de madeira em plantações industriais ou utilizada em integração com a pecuária e a lavoura é um uso em expansão no mundo e no Brasil, possivelmente configurando uma tendência majoritária de investimento. Resta saber se esses investimentos vão configurar um reforço na especialização produtiva, ficando os países centrais com as novas indústrias da bioeconomias, e o Brasil com as plantações de árvores e o setor de papel e celulose.

Referências

BACHA, Carlos José Caetano; STEGE, Alysson Luiz; HARBS, Ricardo. Ciclos de preços de terras agrícolas no Brasil. Revista de Política Agrícola, Brasília v. 25, n. 4, p. 18-37, out./nov./dez. 2016. Disponível em: $<$ https://seer.sede.embrapa.br/index.php/RPA/article/view/1201/1024>. Acesso em:23 nov. 2017.

BEDDINGTON, John et al. Achieving food security in the face of climate change: final report from the Commission on sustainable agriculture and climate change. Copenhagen, Denmark : CGIAR, 2012.

BELLO, Walden. Food wars: crisis alimentaria y políticas de ajuste estructural. Bilbao: Virus Editorial, 2012.

BORRAS JÚNIOR, Saturnino M. et al. The rise of flex crops and commodities: implications for research. Journal of Peasant Studies, London, v. 43, n. 1, p. 93-115, 2016.

BORRAS JÚNIOR, Saturnino M. et al. Land grabbing in Latin America and the Caribbean viewed from broader international perspectives. Santiago, Chile: FAO Regional Office, 14-15 Nov. 2011. Disponível em: <https://mafiadoc.com/land-grabbing-in-latin-america-and-the-caribbean-viewed-from-_5a0034781723dd56b2ed905e.html>. Acesso em: 23 nov. 2017.

BORRAS JÚNIOR, Saturnino M. et al.; Towards understanding the politics of flex crops and commodities: implications for research and policy advocacy. Amsterdam: TNI, 2014. Disponível em: < https://goo.gl/Ys4YQ5 > Acesso em: 05 maio 2017.

BRADESCO. Papel e celulose. Departamento de Pesquisas e Estudos Econômicos [S.1.]: DEPEC-BRADESCO, 2017. Disponível em: <https://goo.gl/NnzAas>. Acesso em: 08 ago. 2017.

INSTITUTO BRASILEIRO DE GEOGRAFIA E ESTATÍSTICA. Censo agropecuário 2006: Brasil, grandes regiões e unidades da federação: segunda apuração. Rio de Janeiro: IBGE, 2009. Disponível em: <https://goo.gl/WbnxmG>. Acesso em: 11 jul. 2017.

BRASIL. Advocacia-Geral da União. Parecer n ${ }^{\circ}$ LA 01, de 19 de agosto de 2010. Diário Oficial da União, Brasília, 23 ago. 2010. Disponível em:< https://goo.gl/4A91mU>. Acesso em: 03 ago. 2017.

BRASIL. Decreto $n^{\circ} 74.965$, de 26 de novembro de 1974. Regulamenta a Lei ${ }^{\circ} 5.709$, de 7 de outubro de 1971, que dispõe sobre a aquisição de imóvel rural por estrangeiro residente no País ou pessoa jurídica estrangeira autorizada a funcionar no Brasil. Diário Oficial da União, Brasília, 27 nov. 1974. Disponível em: < http://www.planalto.gov.br/ccivil 03/decreto/1970-1979/ D74965.htm >. Acesso em: 23 nov. 2017.

BRASIL. Lei $\mathbf{n}^{\circ} \mathbf{5 . 0 7 9}$, de 07 de outubro de 1971. Regula a Aquisição de Imóvel Rural por Estrangeiro Residente no País ou Pessoa Jurídica Estrangeira Autorizada a Funcionar no Brasil, e dá outras Providências. Diário Oficial da União, Brasília, 11 out. 1971. Disponível em: < http:// www.planalto.gov.br/ccivil_03/leis/L5709.htm >. Acesso em: 23 nov. 2017.

BRASIL. Lei $\mathbf{n}^{\circ}$ 6.634, de 02 de maio de 1979. Dispõe sobre a Faixa de Fronteira, altera o Decreto-lei $\mathrm{n}^{\circ} 1.135$, de 3 de dezembro de 1970, e dá outras providências. Diário Oficial da União, Brasília, 03 maio 1979. Disponível em: < http://www.planalto.gov.br/ccivil_03/leis/L6634.htm>. Acesso em: 23 nov. 2017

BRASIL. Lei $\mathbf{n}^{\mathbf{0}} \mathbf{8 . 6 2 9}$, de 25 de fevereiro de 1993. Dispõe sobre a regulamentação dos dispositivos constitucionais relativos à reforma agrária, previstos no Capítulo III, Título VII, da Constituição Federal. Diário Oficial da União, Brasília, 26 fev. 1993. Disponível em: < http://www. planalto.gov.br/ccivil_03/leis/L8629.htm >. Acesso em: 23 nov. 2017. 
BRASIL. Ministério da Ciência e Tecnologia e Inovação. Comissão Técnica Nacional de Biossegurança. Extrato de parecer n ${ }^{\circ} 4408 / 2015$. Brasília: CTNBio, 2015. Disponível em: $<$ https://goo.gl/bsXxKg >. Acesso em: 06 jul. 2017.

BTGPACTUAL. BTG Pactual Timberland Investment Group: overview. Rio de Janeiro: Banco BTGPactual, 2016. Disponível em: <https://goo.gl/8vux7a>. Acesso em: 12 jul. 2017.

CHESNAIS, François (Org.). A finança mundializada. São Paulo: Boitempo, 2010.

CLAPP, Jennifer; HELLEINER, Eric. Troubled futures? The global food crisis and the politics of agricultural derivatives regulation. Review of International Political Economy, London, v.19, n. 2, p. 181-207, 2012

COMISSÃO DE AGRICULTURA, PECUÁRIA, ABASTECIMENTO E DESENVOLVIMENTO RURAL. Projeto de Lei 4.059, de 2012. Regulamenta o art. 190, da Constituição Federal, altera o art. $1^{\circ}$, da Lei ${ }^{\circ} 4.131$, de 3 de setembro de 1962 , o art. $1^{\circ}$ da Lei ${ }^{\circ} 5.868$, de 12 de dezembro de 1972 e o art. $6^{\circ}$ Lei $\mathrm{n}^{\circ} 9.393$, de 19 de dezembro de 1996 e dá outras providências. Brasília: Câmara dos Deputados, 2012. Disponível em: <http://bit.ly/2sL4Yba>. Acesso em: 05 jun. 2017.

CONFEDERAÇÃO NACIONAL DA AGRICULTURA. Venda de terra para estrangeiros traz benefícios? YouTube, 14 de mar de 2017. Disponível em: < ttps://goo.gl/gWi6a4 >. Acesso em: 04 jul. 2017.

CROSBY, Alfred W. Imperialismo ecológico: a expansão biológica da Europa 900-1900. Cambridge: Cambridge University Press, 1986.

DAUVERGNE, Peter; LISTER, Jane. Big brand sustainability: governance prospects and environmental limits. Global Environmental Change, v.2, p. 36-45, 2012.

DAUVERGNE, Peter; LISTER, Jane. Timber. Cambridge: Polity, 2011.

EDELMAN, Marc. Estudios agrarios críticos: tierras, semillas, soberanía alimentaria y derechos de las y los campesinos. Quito: Editorial IAEN, 2016.

ERICKSON Brent; NELSON Janet E.; WINTERS Paul. Perspective on opportunities in industrial biotechnology in renewable chemicals. Biotechnology Journal, v. 7, n. 2, p.176-185, Feb. 2012.

FISCHER, Günther; SHAH, Mahendra. Farmland Investments and Food Security. Laxenburg, Austria: International Institute for Applied Systems Analysis, 2010. Disponível em: < https://goo.gl/t8wW5Y >. Acesso em: 03 jun. 2017.

GASQUES, José Garcia; BASTOS, Eliana Teles; VALDES, Constanza. Preço da terra no Brasil. In: CONGRESSO DA SOCIEDADE BRASILEIRA DE ECONOMIA, ADMINISTRAÇÃO E SOCIOLOGIA RURAL, 46., 2008, Rio Branco. Anais ... Rio Branco, AC : SOBER, 2008. Disponível em: < https://goo.gl/Qo6MWz >. Acesso em: 30 jun. 2017.

GEISLER, Charles. Trophy lands: why elites acquire land and why it matters. Canadian Journal of Development Studies / Revue canadienne d'études du développement, v. 36, n. 2, p. 241$257,2015$.

GILPIN, Robert. A Economia das Relações Internacionais. Brasília: Editora UnB, 2002.

HIGH LEVEL PANEL OF EXPERTS. Sustainable forestry for food security and nutrition: a report by the High Level Panel of Experts on Food Security and Nutrition of the Committee on World Food Security, Rome: CFS;HLPE, 2017. Disponível em: < https://goo.gl/qPGaEA >. Acesso em: 23 jul. 2017.

HORA, André Barros da. Análise da formação da base florestal plantada para fins industriais no Brasil sob uma perspectiva histórica. BNDES Setorial, Rio de Janeiro, n. 42, p. 383-426, 2015.

HOUTART, François. A agroenergia: soluções para o clima ou saída da crise para o capital? Petrópolis: Vozes, 2010.

INDÚSTRIA BRASILEIRA DE ÁRVORES. [Relatório anual] Ibá 2014. Brasília: IBÁ, 2014. Disponível em: < https://goo.gl/tWzz5g >. Acesso em: 07 ago. 2017.

IBÁ. INDÚSTRIA BRASILEIRA DE ÁRVORES. [Relatório anual] Ibá 2015. Brasília: IBÁ, 2015. Disponível em: < https://goo.gl/XqSSr3 >. Acesso em: 07 ago. 2017.

INDÚSTRIA BRASILEIRA DE ÁRVORES. IBÁ: Indústria Brasileira de Árvores: brazilian tree industry. São Paulo: IBÁ, 2016. Disponível em: <https://goo.gl/EfLpbp>. Acesso em: 07 ago. 2017. INSTITUTO BRASILEIRO DE GEOGRAFIA E ESTATÍSTICA. Censo agropecuário. Rio de Janeiro: IBGE, 2009. Disponível em: < https://goo.gl/WbnxmG >. Acesso em: 11 jul. 2017.

INSTITUTO NACIONAL DE COLONIZAÇÃO E REFORMA AGRÁRIA. 1114 Módulo de exploração indefinida MEI. Brasília: INCRA, 2014. Disponível em: <https://goo.gl/ExSR9v>. Acesso em: 03 jul. 2017. 
INSTITUTO NACIONAL DE COLONIZAÇÃO E REFORMA AGRÁRIA. Cadastro de imóveis rurais: situação jurídica: titularidade particular. Brasília: Instituto Nacional de Colonização e Reforma Agrária INCRA, 2016a. Disponível em: <https://goo.gl/TF4KFt>Acesso em: 01 jul. 2017.

INSTITUTO NACIONAL DE COLONIZAÇÃO E REFORMA AGRÁRIA. Perguntas e respostas sobre a aquisição e o arrendamento de terras por estrangeiros. Brasília: INCRA, 2017. Disponível em: <https://goo.gl/kCKKR8>. Acesso em: 03 jul. 2017.

INSTITUTO NACIONAL DE COLONIZAÇÃO E REFORMA AGRÁRIA. Estatísticas de imóveis rurais. Brasília: INCRA, 2016b. Disponível em: < http://www.incra.gov.br/estrutura-fundiaria/estat-sticas-de-im-veis-rurais->Acesso em: 01 jul. 2017.

INSTITUTO NACIONAL DE COLONIZAÇÃO E REFORMA AGRÁRIA. Instrução normativa n. 76. Brasília: INCRA, 2013. Disponível em: $<$ http://www.incra.gov.br/media/imprensa/ IN_76_P.pdf $>$. Acesso em: 01 jul. 2017.

INTERNATIONAL SERVICE FOR THE ACQUISITION OF AGRI-BIOTECH APPLICATIONS Brief 52: global status of commercialized Biotech/GM crops: 2016. Ithaca: ISAAA, 2016. Disponível em: <https://goo.gl/5Ksuxj>. Acesso em: 04 ago. 2017.

KRÖGER, Markus. The political economy of 'flex trees': a preliminary analysis. The Journal of Peasant Studies, London, v. 43, n.4, p. 886-909, 2016.

KRÖGER, Markus. The political economy of global tree plantation expansion: a review. The Journal of Peasant Studies, London, v. 41, n. 2, p. 235-261, 2014.

LIMA FILHO, Rafael Ribeiro de; AGUIAR, Gustavo Adolpho Maranhão; TORRES, Alcides. Eucalipto : rentabilidade da produção no Brasil. Revista Agroanalysis, Rio de Janeiro, jun. 2014. Disponível em: < https://goo.gl/rFofsy > Acesso em: 13 jul. 2017.

LINKLATER, Andro. Owning the Earth: the transforming history of land ownership. London: Bloomsbury, 2013.

MAGDOFF, Fred; TOKAR, Brian (Ed.). Agriculture and food in crisis: conflict, resistance, and renewal. New York: Monthly Review Press, 2010.

McMICHAEL, Philip. The world food crisis in historical perspective. In: MAGDOFF, Fred; TOKAR, Brian (Ed.). Agriculture and food in crisis: conflict, resistance, and renewal. New York: Monthly Review Press, 2010. p. 51-67.

NALI, Eduardo Christensen; RIBEIRO, Leonardo Brandão Nader Magliano; HORA, André Barros da. Biorrefinaria integrada à indústria de celulose no Brasil: oportunidade ou necessidade? BNDES Setorial, Rio de Janeiro, n. 43, p. 257-294, 2016. Disponível em : < https://goo.gl/RaaMiF > Acesso em: 05 ago. 2017.

ORGANIZAÇÃO DAS NACÕES UNIDAS PARA ALIMENTAÇÃO E AGRICULTURA. Perspectivas agrícolas 2015-2024. [S.1.]: OCDE/FAO, 2015. Disponível em: <https://goo.gl/ry4QGi>. Acesso em: 07 fev. 2017.

OLIVEIRA, Ariovaldo Umbelino de. A mundialização da agricultura brasileira. São Paulo: Iãnde editorial, 2016. Disponível em: < https://goo.gl/f8SrxR_> Acesso em: 03 abr. 2017.

OVERBEEK Winfridus; KRÖGER Markus; GERBER Julien-Françoes. Um panorama das plantações industriais de árvores no Sul global: conflitos, tendências e lutas de resistência. Relatório EJOLT , n. 3,2012.

PAULA, Nilson Maciel de; SANTOS, Valéria Faria; PEREIRA, Wellington Silva. A financeirização das commodities agrícolas e o sistema agroalimentar. Estudos Sociedade e Agricultura, Rio de Janeiro, ano 23, v. 2, out. 2015.

PORTAL BRASIL. Preço médio das terras no Brasil aumentou $300 \%$ nos últimos anos. Brasília: Governo do Brasil, 02 mar. 2015. Disponível em: < https://goo.gl/kecmGk>. Acesso em: 05 jul. 2017.

QUÍMICA verde no Brasil: 2010-2030. Ed. rev. e atual. Brasília: Centro de Gestão e Estudos Estratégicos, 2010. Disponível em: < https://goo.gl/wMLbyj > Acesso em: 01 ago. 2017.

RODRIGUES, Felipe Leonardo. Aquisição de imóveis rurais por estrangeiros: Atualidade. Colégio Notarial do Brasil. 07 mar. 2016. Disponível em: < https://goo.gl/YGvPCi >. Acesso em: 06 jul. 2017.

SAUER, Sérgio; LEITE, Sergio Pereira. Expansão agrícola, preços e apropriação de terra por estrangeiros no brasil. RESR, Piracicaba, SP, v. 50, n. 3, p. 503-524, 2012.

SCREPANTI, Ernesto. Global Imperialism and the Great Crisis: the uncertain future of capitalism. New York: NYU Press, 2014. 
(ei) estudos internacionais • Belo Horizonte, ISSN 2317-773X, v.5 n.2 (2017), p.132 - 154

SISTEMA NACIONAL DE INFORMAÇÕES FLORESTAIS. Definição de Floresta. Brasília: Serviço Florestal Brasileiro, 2017. Disponível em: < https://goo.gl/pAxyhT > . Acesso em: 01 ago. 2017.

SISTEMA NACIONAL DE INFORMAÇÕES FLORESTAIS. Produção Florestal - Madeireiros. Serviço Florestal Brasileiro, 2017a. Disponível em: < https://goo.gl/pMu4DB > Acessado em: 01 ago. 2017b.

TRUFFI, Renato. O governo Temer prepara MP para a venda de terras a estrangeiros. Carta Capital, São Paulo, 16 fev. 2017. Disponível em: < https://goo.gl/fqtvK5 >. Acesso em: 04 jul. 2017. 